\title{
Immobilization of carboxypeptidase from Sulfolobus solfataricus on magnetic nanoparticles improves enzyme stability and functionality in organic media
}

Silvia Sommaruga' ${ }^{1}$ Elisabetta Galbiati ${ }^{1}$, Jesus Peñaranda-Avila' ${ }^{1}$, Chiara Brambilla ${ }^{1}$, Paolo Tortora ${ }^{1 *}$, Miriam Colombo ${ }^{1}$ and Davide Prosperi, ${ }^{1,2}$

\begin{abstract}
Background: Superparamagnetic iron oxide nanoparticles (MNP) offer several advantages for applications in biomedical and biotechnological research. In particular, MNP-based immobilization of enzymes allows high surface-to-volume ratio, good dispersibility, easy separation of enzymes from the reaction mixture, and reuse by applying an external magnetic field. In a biotechnological perspective, extremophilic enzymes hold great promise as they often can be used under non-conventional harsh conditions, which may result in substrate transformations that are not achievable with normal enzymes. This prompted us to investigate the effect of MNP bioconjugation on the catalytic properties of a thermostable carboxypeptidase from the hyperthermophilic archaeon Sulfolobus solfataricus (CPSso), which exhibits catalytic properties that are useful in synthetic processes.

Results: CPSso was immobilized onto silica-coated iron oxide nanoparticles via NiNTA-His tag site-directed conjugation. Following the immobilization, CPSso acquired distinctly higher long-term stability at room temperature compared to the free native enzyme, which, in contrast, underwent extensive inactivation after $72 \mathrm{~h}$ incubation, thus suggesting a potential utilization of this enzyme under low energy consumption. Moreover, CPSso conjugation also resulted in a significantly higher stability in organic solvents at $40^{\circ} \mathrm{C}$, which made it possible to synthesize $\mathrm{N}$-blocked amino acids in remarkably higher yields compared to those of free enzyme.

Conclusions: The nanobioconjugate of CPSso immobilized on silica-coated magnetic nanoparticles exhibited enhanced stability in aqueous media at room temperature as well as in different organic solvents. The improved stability in ethanol paves the way to possible applications of immobilized CPSso, in particular as a biocatalyst for the synthesis of $\mathrm{N}$-blocked amino acids. Another potential application might be amino acid racemate resolution, a critical and expensive step in chemical synthesis.
\end{abstract}

Keywords: Carboxypeptidase, Magnetic nanoparticles, His-tag immobilization, Enzyme stability, Hyperthermophilic microorganisms

\footnotetext{
* Correspondence: paolo.tortora@unimib.it

'Dipartimento di Biotecnologie e Bioscienze, Università di Milano-Bicocca,

Piazza della Scienza 2, Milano 20126, Italy

Full list of author information is available at the end of the article
} 


\section{Background}

Due to their unique magnetic properties, superparamagnetic iron oxide nanoparticles (MNP) represent a wellknown and effective nanosystem for applications in biomedical and biotechnological research. In fact, MNP are being developed as drug carriers [1,2], imaging agents $[1,3]$, analytical probes $[4,5]$ and recyclable support for enzyme immobilization [6,7].

Compared with chemical catalysis, enzyme-mediated reactions allow for more specific chemo-, regio-, and stereoselectivity in organic synthesis [8]. However, long-term stability and recyclability of enzymes have been considered the main limitations to their extensive utilization [9].

Recently, several nanoparticles have been employed to improve traditional enzyme immobilization methods in order to enhance loading, activity and stability of enzymes and to reduce the biocatalyst costs in industrial biotechnology $[10,11]$. In particular, MNP-based immobilization of enzymes presents several advantages, including (i) high surface-to-volume ratio offered by nanosize magnetic beads, (ii) good dispersibility, (iii) easy separation of enzymes from the reaction mixture, and (iv) reuse by applying an external magnetic field [12]. One of the crucial points in protein immobilization on nanoscale solid surfaces is that structural modifications may occur, which could affect protein activity and stability to different extents depending on the protein and the conjugation strategy [13]. For this reason, there has been an increasing interest in developing new reliable approaches for the immobilization of enzymes on magnetic nanoparticles [14-16]. However, although great efforts have been made for this purpose, the actual effect of immobilization on enzyme functionality is still poorly understood. Furthermore, no such studies involving enzymes from extremophile microorganisms have been carried out so far.

Extremophilic enzymes hold great promise in industrial biotechnology, as they can often be used under nonconventional harsh conditions, which may result in substrate transformations that are not achievable with normal enzymes [17].

In this work, we investigated the effect of MNP bioconjugation on the catalytic properties of a thermostable carboxypeptidase from Sulfolobus solfataricus (CPSso). CPSso is a heat- and pressure-resistant zinc-metalloprotease consisting of four identical $43 \mathrm{kDa}$ subunits [17-20]. The catalytic and kinetic mechanisms of CPSso have been well established and were confirmed by a 3D model that was developed and validated in the past years [21,22]. CPSso exhibits nonconventional catalytic properties that are useful in several synthetic processes. First, it removes any amino acid from the C-terminus of short peptides, with the sole exception of proline, and also hydrolyzes N-blocked amino acids, thus acting as an aminoacylase [22]. Second, despite its remarkable thermophilicity, it maintains a significant fraction of its maximal activity even at room temperature. Finally, CPSso maintains a significant activity in solvent mixtures even at high content of organic fraction [23]. These peculiar properties highlight the biotechnological potential of this enzyme, in particular to achieve the synthesis of N-blocked amino acid in organic media.

\section{Results}

\section{Synthesis of $\mathrm{Ni}^{2+}$-functionalized silica-coated magnetic} nanoparticles (NiNTASiMNP)

High-quality magnetite nanocrystals were synthesized in organic solvents and transferred to water phase using tetramethylammonium hydroxide (TMAOH) as previously described [24]. Next, the water-soluble iron oxide nanoparticles were individually coated with a $10 \mathrm{~nm}$ thick silica shell by reaction with tetraethoxysilane (TEOS) in aqueous ammonia and further reacted with the chelating agent ICPTES-NTA and $\mathrm{NiCl}_{2}$, [25] resulting in fully armed $\mathrm{Ni}^{2+}$ functionalized nanoparticle (NiNTASiMNP). The overall synthesis procedure is summarized in Figure 1. In Figure 2, TEM images show that the final size of SiMNP was $30 \pm 3 \mathrm{~nm}$ with a magnetic core of $10 \pm 1 \mathrm{~nm}$, indicating a homogeneous sample of silica-coated magnetic nanoparticles. Hydrodynamic diameter of SiMNP in ethanol was $80.4 \pm 2.3 \mathrm{~nm}$, as determined by dynamic light scattering, which remarkably increased to $128.3 \pm 3.7 \mathrm{~nm}$ as a consequence of NTA functionalization. Such a difference accounts for a transient loss in nanoparticle stability forming small aggregates after reaction with ICPTESNTA. However, stable nanoparticle dispersion was recovered after $\mathrm{Ni}^{2+}$ chelation, resulting in hydrodynamic

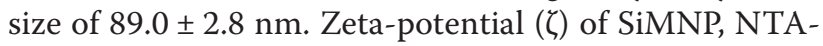
SiMNP and NiNTASiMNP in water was also investigated. SiMNP and NTASiMNP were negatively charged $(-19.11 \pm 1.70 \mathrm{mV}$ and $-24.42 \pm 1.03 \mathrm{mV}$, respectively), the second being more negative due to the presence of NTA carboxylic groups. The capture of $\mathrm{Ni}^{2+}$ ions by the external carboxylic groups of NTA resulted in a more positive charge in NiNTASiMNP $(-12.00 \pm 1.03 \mathrm{mV})$. The amount of $\mathrm{Ni}^{2+}$ ions captured by NTASiMNP was quantified by inductively coupled plasma optical emission spectrometry (ICP-OES), resulting in $41 \mathrm{ng} \mathrm{Ni}$ per mg nanoparticles.

\section{Immobilization of CPSso on NiNTASiMNP}

CPSso protein containing $6 \times$ His tag was produced in Escherichia coli and purified by Ni-chelate affinity chromatography, as previously described [21]. Subsequent $\mathrm{Ni}^{2+}$ capture by NTA groups of NTASiMNP promoted the active $\mathrm{Ni}^{2+}$-NTA affinity-oriented immobilization of His-tagged CPSso (Figure 1). The conjugation reaction was performed at room temperature by incubating NiNTASiMNP $(1 \mathrm{mg})$ with purified CPSso $(200 \mu \mathrm{g})$. The 


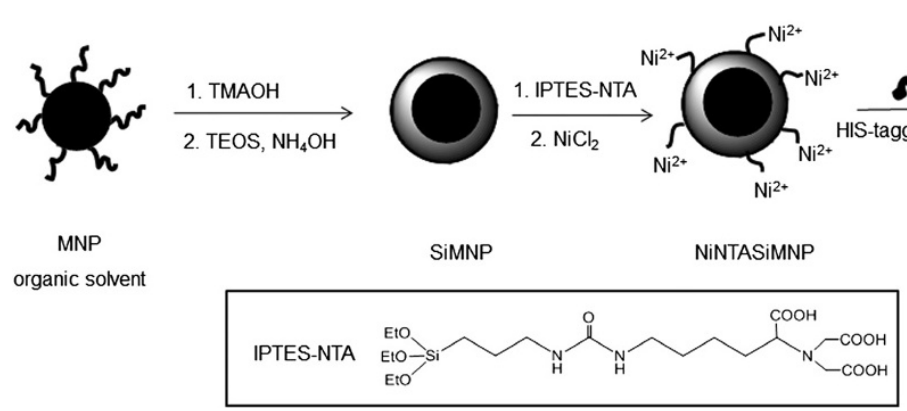

Figure 1 Procedure of CPSso immobilization on NiNTASiMNP.

resulting MNP-CPSso was isolated from unreacted CPSso by centrifugation and washed three times. By measuring the amount of protein found in the supernatants after the enzyme binding process, we determined an amount of CPSso immobilized on nanoparticles of $150 \mu \mathrm{g}$ per mg of MNP-CPSso. The average CPSso loading was estimated to be about 2 molecules per nanoparticle. To check that the conjugation reaction occurred specifically to $\mathrm{Ni}^{2+}$ and His tag, CPSso was incubated in parallel with nonfunctionalized nanoparticles (NTASiMNP). Then, reaction mixtures were washed, and bound and unbound CPSso determined enzymatically. Non-specifically bound activity was only $4.5 \%$ of that bound through the NiNTA linker (Additional file 1: Table S1). These data confirm that CPSSo immobilization is mediated by the interaction between $\mathrm{Ni}^{2+}$ and His tag. After immobilization, CPSso substantially retained its activity, as shown by comparison of equal amount of free and bound CPSso (data not shown).

\section{Assessment of the catalytic stability of MNP-CPSso}

The catalytic stability of free and conjugated CPSso was analyzed by monitoring the inactivation profiles of the samples incubated in aqueous solution at three different temperatures $\left(25^{\circ} \mathrm{C}, 40^{\circ} \mathrm{C}\right.$ and $75^{\circ} \mathrm{C}$, respectively) and, subsequently, in the presence of organic solvents, i.e. dimethylformamide (DMF) or ethanol, at different water ratios.
As expected, CPSso was fully active after $30 \mathrm{~min}$ incubation at $75^{\circ} \mathrm{C}$ in aqueous buffer, while MNP-CPSso proved to be less stable (Figure $3 \mathrm{a}$ ). No significant differences were observed in the stability of free and conjugated enzyme at $40^{\circ} \mathrm{C}$ (Figure $3 \mathrm{~b}$ ). Functionality profiles obtained at $25^{\circ} \mathrm{C}$ showed that free CPSso gradually lost its activity resulting in a complete inactivation after 96 h. In such a case, however, enzyme conjugation led to a substantial increase in stability, up to $85 \%$ of initial activity being retained after 96 h (Figure 3c). A tentative interpretation of these results is presented in the section Discussion.

The inactivation profiles obtained at $40^{\circ} \mathrm{C}$ and different concentrations of DMF indicate that CPSso gradually lost its activity by increasing the organic component in the solvent mixture, while the nanobioconiugate retained $80 \%$ of residual activity even in the presence of $80 \%$ DMF (Figure 3d-f). The results obtained in the presence of ethanol at $40^{\circ} \mathrm{C}$ and various concentrations are of particular interest. The inactivation profiles show that CPSso had a residual activity of $50 \%$ after $6 \mathrm{~h}$, which decreased to $20 \%$ after $24 \mathrm{~h}$ incubation (Figure $3 \mathrm{~g}$-i). However, MNPCPSso revealed a significantly improved stability in ethanol at the different tested concentrations compared with free CPSso, up to $80-90 \%$ of residual activity after $6 \mathrm{~h}$, and $70 \%$ after $24 \mathrm{~h}$ incubation in $80 \%$ ethanol being retained.

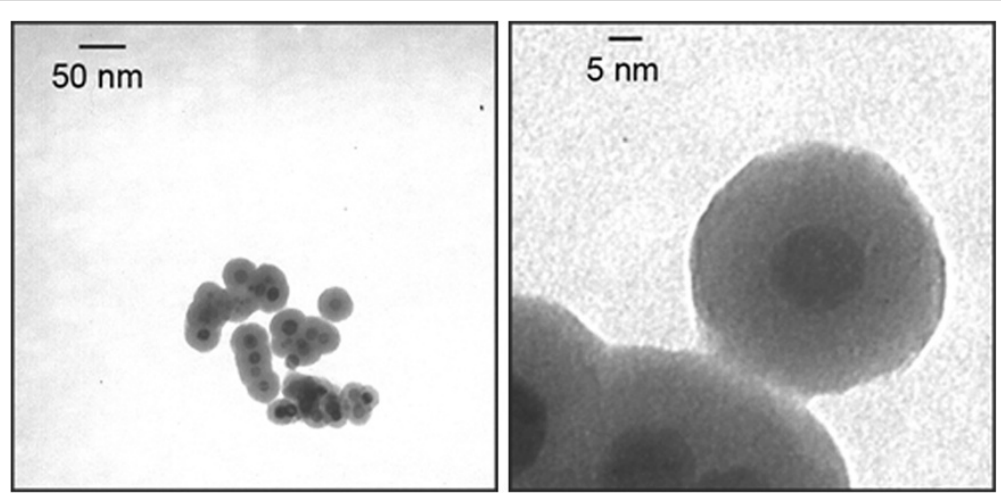

Figure 2 TEM images of synthesized SiMNP at two different magnifications. 


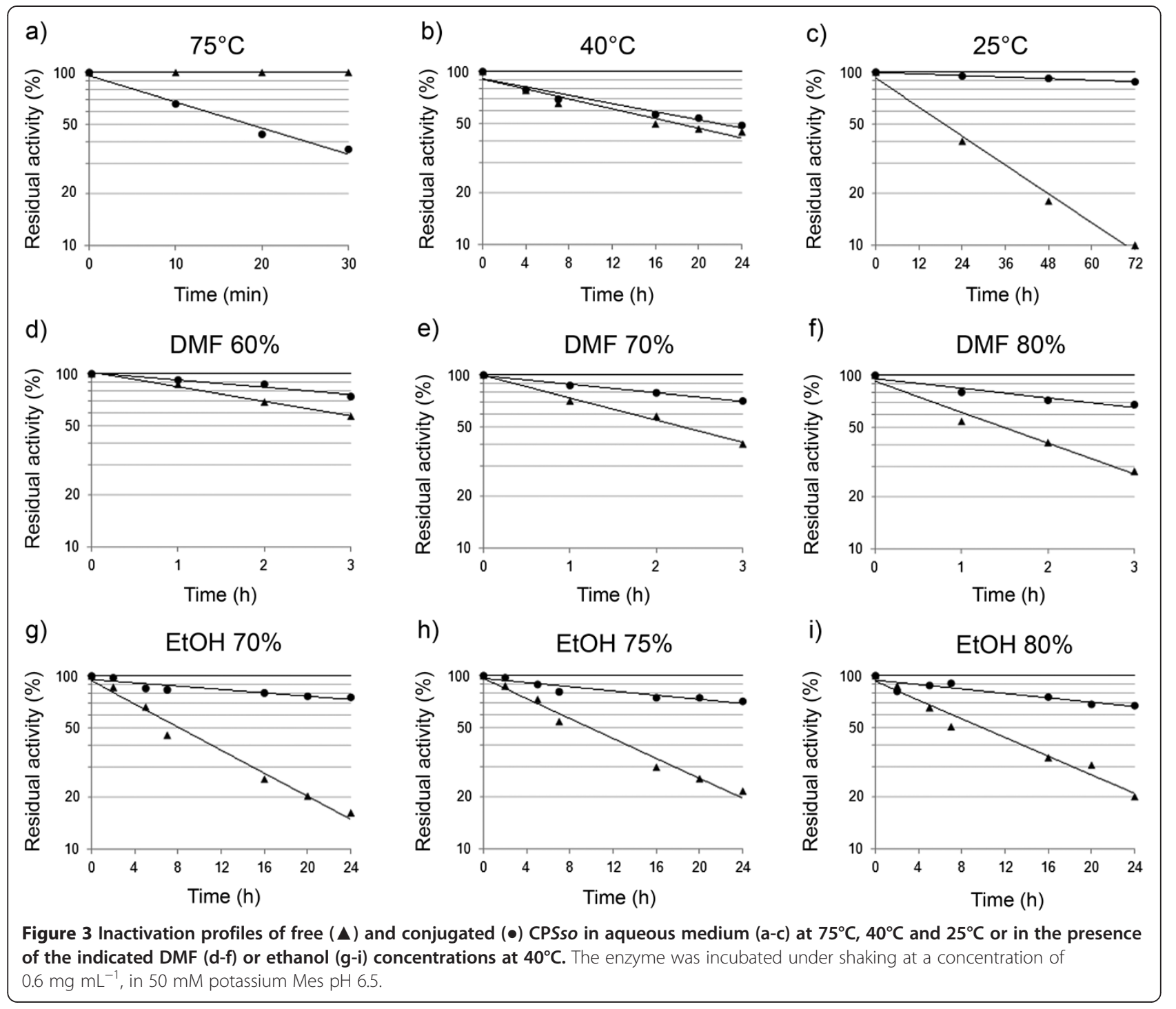

\section{Synthesis of N-blocked amino acids promoted by}

\section{MNP-CPSso}

Preliminary experiments were carried out in order to select the water-cosolvent system and the chemical-physical parameters most suitable to promote the synthesis of
$N$-blocked amino acids by CPSso, using arginine and benzoate as a model system (Figure 4). Our results show that the best rate of benzoyl-arginine (BA) synthesis was obtained in $70 \%$ ethanol at $\mathrm{pH} 6.5$ and $40^{\circ} \mathrm{C}$ after $6 \mathrm{~h}$ of incubation, using $10 \mathrm{U} \mathrm{mL}^{-1} \mathrm{CPSso}, 0.4 \mathrm{M}$ benzoate and

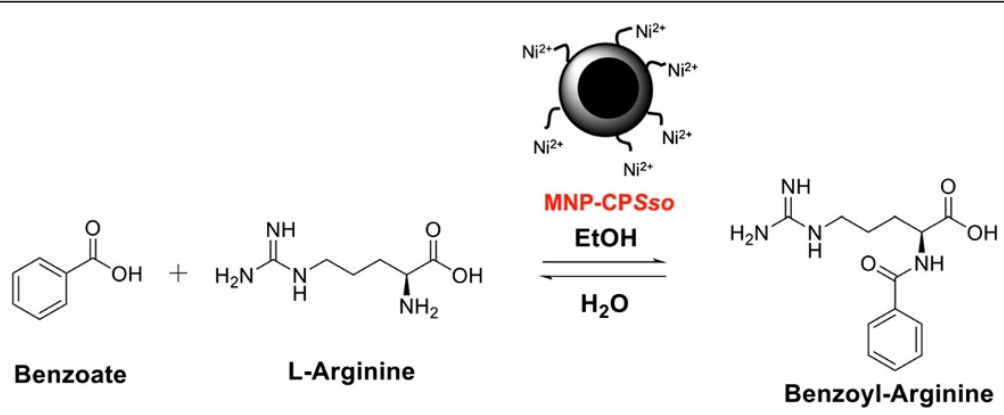

Figure 4 MNP-CPSso-catalyzed synthesis of an N-blocked amino acid. 
0.1 M arginine (data not shown). Next, BA synthesis was performed using both free CPSso and MNP-CPSso under the aforementioned optimal conditions. By taking advantage of the remarkable enzyme stability in organic solvent, higher ethanol concentration (75\% and $80 \%$ ) and a longer incubation time $(24 \mathrm{~h})$, were also tested. The results obtained after a 6-h incubation (Figure 5) show a similar synthetic rate for free and conjugated enzyme in $70 \%$ ethanol. However, at higher ethanol concentrations, only MNPCPSso could synthesize appreciable amounts of BA, although in much lower yields. Remarkably, when the synthesis was extended to $24 \mathrm{~h}$, higher yields were observed, with the sole exception of unbound CPSso in 70\% ethanol. In particular, at $70-75 \%$ ethanol, far better yields were attained when using MNP-CPSso (Figure 5). Under all adopted conditions, no detectable enzyme activity was found in the reaction mixture after removal of the MNPs (data not shown).

The activity of NiNTASiMNP was retained without significant drop in functionality for three-times recycled uses in comparison with the initial activity, comparable with other systems of similar efficiency [26].

\section{Discussion}

In our ongoing effort in designing innovative approaches for the orientation-controlled conjugation of proteins on metal-based nanoparticles for biotechnological and biomedical applications [5,27-31], we have recently investigated the modulation of the structural properties of the immobilized protein from a biophysical point of view [13]. In the present paper, we report the results of a study conducted on a hyperthermophilic enzyme, namely CPSso, aimed at determining the effect of its immobilization on superparamagnetic nanoparticles on the biological activity of the enzyme.

The nanobioconjugate was obtained by affinity-oriented immobilization of His-tagged CPSso on silica-coated magnetic nanoparticles functionalized with Ni-NTA groups (NiNTASiMNP). The procedure for the synthesis of NiNTASiMNP is illustrated in Figure 1 and the resulting functionalized $\mathrm{Fe}_{3} \mathrm{O}_{4} @$ silica core-shell nanoparticles gave a stable dispersion in aqueous environment, as determined by dynamic light scattering analysis.

An important requirement for protein immobilization is that the matrix should provide a biocompatible and inert environment, i.e. it should not interfere with the native structure of the protein, which would thereby compromise its biological activity. Thus, we measured the enzymatic activity of free and immobilized CPSso and confirmed that its activity was preserved after conjugation. Next, we evaluated the protein activities in an aqueous milieu to assess the effect of conjugation on the stability of the hyperthermophilic enzyme in dependence of the temperature. Noteworthy, in this respect, is the substantial stability at room temperature of MNP-conjugated CPSso, unlike the free enzyme, which should make it possible to perform transformations without the use of energy for heating or cooling the reaction environment, otherwise needed for maintaining enzyme stability. In a theoretical perspective, this might be rationalized on the basis of the following considerations. As free enzyme undergoes inactivation at $40^{\circ} \mathrm{C}$ and $25^{\circ} \mathrm{C}$, but not at $75^{\circ} \mathrm{C}$, in agreement with our previous report [22], this fits with the "cold denaturation" pattern, which is believed to be a general phenomenon in protein chemistry [32]. In the case of free CPSso, optimum stability temperature might be at, or close to $75^{\circ} \mathrm{C}$, as significant inactivation was previously observed at $85^{\circ} \mathrm{C}$ [33]. In contrast, the conjugated enzyme was essentially stable at $25^{\circ} \mathrm{C}$ and underwent progressive destabilization on increasing temperature, suggestive of a substantial downshift of the stability optimum. Based on enzyme activity decay constants determined at the three temperatures, we assessed an activation enthalpy $\left(\Delta \mathrm{H}^{*}\right)$ of enzyme inactivation around $150 \mathrm{~kJ} \cdot \mathrm{mol}^{-1}$ for the conjugated enzyme, well below values close to $500 \mathrm{~kJ} \cdot \mathrm{mol}^{-1}$ determined for the free form $[33,22]$. As the enzyme retains its activity after conjugation, it must retain its overall structure as well. Thus, the dramatic drop in $\Delta \mathrm{H}^{\dagger}$ of bound with respect to free enzyme, is suggestive of major conformational constraints of the

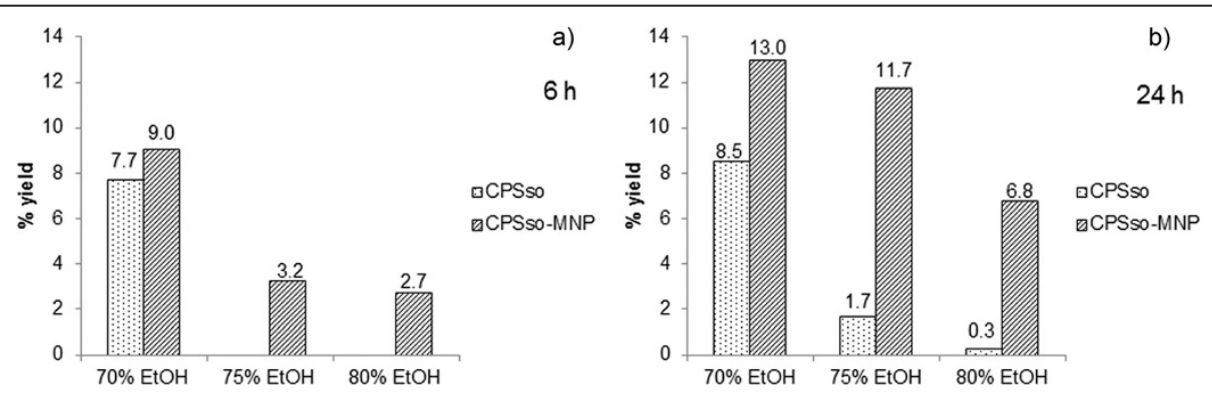

Figure 5 Synthesis of benzoyl-arginine catalysed by free and conjugated CPSso in the presence of different ethanol concentration. $0.4 \mathrm{M}$ benzoate, $0.1 \mathrm{M}$ arginine were incubated with $5 \mathrm{U} \mathrm{mL}^{-1} \mathrm{CPSSO}$ at $40^{\circ} \mathrm{C}$ in $50 \mathrm{mM}$ potassium Mes, $\mathrm{pH} 6.5$, and ethanol at the indicated concentrations. After a $6 \mathrm{~h}$ (a) or $24 \mathrm{~h}$ (b) incubation, the amount of benzoyl-arginine synthesized was determined spectrophotometrically. 
transition state as a result of immobilization. This is confirmed by an activation entropy value $\left(\Delta \mathrm{S}^{\ddagger}\right)$ close to zero (as determined from the data in Figure 3a to c), to be compared with $1.1 \mathrm{~kJ} \cdot \mathrm{mol}^{-1} \mathrm{~K}^{-1}$ of the free enzyme [33,22].

It is well-known that enzyme immobilization generally results in increased stability toward the denaturing effect of water-soluble organic solvents [34]. Also, it is believed that such polar solvents first strip water from the surface of the protein, then strongly compete for intramolecular hydrogen bonds, with resulting protein unfolding [35]. In the case of CPSso, the conjugation quite likely limits its conformational flexibility, as above outlined, which may partially prevent the solvent from penetrating the protein interior. The stronger effect of DMF with respect to ethanol fits well with its higher polarity and "denaturing capacity", as previously defined [36]. Remarkably, we found that at $40^{\circ} \mathrm{C}$ the conjugated enzyme was even more stable in $80 \%$ ethanol than in water.

Improved stability of MNP-CPSso in organic solvent is relevant to possible industrial applications of the enzyme as a biocatalyst in synthetic reactions carried out in organic environment. In particular, also thanks to its broad substrate specificity, CPSso could be an ideal candidate as a biocatalyst for the synthesis of $N$-blocked amino acids in water-cosolvent mixtures following the thermodynamic method. Actually, we previously found that the enzyme is capable of both hydrolyzing N-blocked amino acids in aqueous solution [20], and catalyzing the synthetic reaction in organic solvents [33], irrespective of the amino acid involved (with the sole exception of proline). The presence of organic solvents in solution is in fact deemed necessary to shift the equilibrium toward the formation of the peptide bond, due to their generally low dielectric constant and the consequent prevalence of undissociated forms of carboxylic and amino groups, which are indeed the reactive species in amide linkage formation [37]. It is worthwhile to be mentioned, in this respect, that at 70-75\% ethanol, MNP-CPSso catalyzed significant synthesis of benzoyl-arginine (BA) (Figure 5), which is promising for possible industrial applications, whereas the free enzyme's performance was very poor under the same conditions. The lower levels of BA produced in $75 \%$ and $80 \%$ compared to $70 \%$ ethanol, are likely due to enzyme inhibition by the organic solvent. In fact, it is well known that the kinetic parameters, $\mathrm{k}_{\mathrm{cat}}$ and $\mathrm{K}_{\mathrm{m}}$, are strongly affected by organic solvents [38].

\section{Conclusions}

We developed a nanobioconjugate of CPSso immobilized on silica-coated magnetic nanoparticles, which exhibited enhanced stability in aqueous media at room temperature as well as in different organic solvents. The improved stability in ethanol paves the way to possible applications of immobilized CPSso; in particular, our results show that the enzyme could be employed as a biocatalyst for the synthesis of $N$-blocked amino acids. Another potential application might be amino acid racemate resolution, a critical and expensive step in chemical synthesis. This could be accomplished by chemically synthesizing $N$-blocked racemic amino acid mixtures, followed by CPSso-catalyzed selective hydrolysis of the blocking group from the L-enantiomer.

\section{Methods}

\section{Chemicals and Instrumentation}

All chemicals were purchased from Sigma-Aldrich (St. Louis, MO) and used as received. Water was deionized and ultrafiltered by a MilliQ apparatus from Millipore Corporation (Billerica, MA) before use. Transmission electron microscopy (TEM) images were obtained by a Zeiss EM-109 microscope operating at $80 \mathrm{kV}$, available at the "Centro di Microscopia Elettronica per le Nanotecnologie applicate alla medicina" (CMENA, University of Milan). Dynamic light scattering (DLS) measurements were performed at $90^{\circ}$ with a 90 Plus Particle Size Analyzer from Brookhaven Instruments Corporation (Holtsville, $\mathrm{NY}$ ), working at $15 \mathrm{~mW}$ of a solid state laser $(\lambda=661 \mathrm{~nm})$. Zeta-potential $(\zeta)$ measurements were performed on the same instrument, equipped with a couple of AQ-809 electrodes, and analyses were processed by a ZetaPlus software. Viscosity and refractive index of pure water were used to characterize the solvent. Nanoparticles were dispersed in the solvent and sonicated in a S15H Elmasonic apparatus (Elma, Singen, Germany) before analysis. Final sample concentration used for measurements was typically of $5 \mu \mathrm{g} \mathrm{mL} \mathrm{m}^{-1}$. For ICP-OES analysis, $2 \mathrm{ml}$ of the NiNTASiMNP dispersion $\left(5 \mathrm{mg} \mathrm{mL}^{-1}\right)$ was measured in triplicate with Optima 7000 DV ICP-OES (Perkin Elmer).

\section{Synthesis of NiNTASiMNP}

Magnetic nanoparticles (MNP) were synthesized in organic solvent by solvothermal decomposition as described in our previous work [30]. The $8 \mathrm{~nm}$ iron oxide nanoparticles coated with oleic acid dissolved in chloroform $(20 \mathrm{mg}$, $6.7 \mathrm{~mL}$ ) were treated with an aqueous solution of tetramethylammonium hydroxide (TMAOH, $0.6 \mathrm{~g}$ in $20 \mathrm{ml}$ ) overnight under vigorous stirring at room temperature $[27,30,39]$. The organic solution containing the surfactant was removed by centrifugation at $1000 \mathrm{rpm}(3 \mathrm{~min})$. The aqueous solution of TMAOH-coated MNP (20 mg) was concentrated in Amicon Ultra 100.000 MWCO (Millipore) (3000 rpm, $5 \mathrm{~min}$ ). The resulting nanoparticle dispersion $(1.2 \mathrm{~mL})$ was added to a mixture of EtOH $(3 \mathrm{~mL})$ and aqueous ammonia ( $75 \mu \mathrm{L}, 28 \%$ by weight), then, a solution of tetraethyl orthosilicate (TEOS) in ethanol $(45 \mu \mathrm{L}$ in $500 \mu \mathrm{L} \mathrm{EtOH}$ ) was added dropwise and stirred overnight in order to obtain individual-particle silica coating. The precipitate was collected by magnet, washed three 
times with $\mathrm{EtOH}$ and dried under vacuum. The resulting nanoparticles were dispersed in EtOH (33 mL) (SiMNP).

For the synthesis of ICPTES-NTA, a solution of $\varepsilon-(N-$ benzyloxycarbonyl)lysine (1) $(1.2 \mathrm{~g}, 4.2 \mathrm{mmol})$ in $1.5 \mathrm{M}$ $\mathrm{NaOH}(15 \mathrm{~mL})$ was added dropwise to a solution of bromoacetic acid $(2.5 \mathrm{~g}, 18 \mathrm{mmol})$ in $1.5 \mathrm{M} \mathrm{NaOH}(9 \mathrm{~mL})$ at $0^{\circ} \mathrm{C}$ over $2 \mathrm{~h}$. The mixture was allowed to warm up to $18^{\circ} \mathrm{C}$, stirred at this temperature overnight, then at $50^{\circ} \mathrm{C}$ for $2 \mathrm{~h}$. The cooled reaction mixture was treated dropwise with $1 \mathrm{M} \mathrm{HCl}(24 \mathrm{~mL})$. The white precipitate was filtered off, washed with $0.1 \mathrm{M} \mathrm{HCl}(12 \mathrm{~mL})$ and water $(2 \times 12 \mathrm{~mL})$, then dried under vacuum and then ovendried at $90^{\circ} \mathrm{C}$ to give the triacid derivative (2) [40].

The product $(2 \mathrm{~g})$ was dissolved in $50 \mathrm{~mL}$ of $\mathrm{MeOH} /$ $\mathrm{H}_{2} \mathrm{O}$ (20:1) under sonication to dissolve the product and, after the addition of a spatula tip of $5 \% \mathrm{Pd} / \mathrm{C}$, hydrogenated at room temperature and atmospheric pressure. Total hydrogenation of compound was achieved after $90 \mathrm{~min}$ as monitored by TLC in $\mathrm{CH}_{3} \mathrm{CN} / \mathrm{H}_{2} \mathrm{O}(4: 1)$, visualized by charring with a solution of $\left(\mathrm{NH}_{4}\right)_{6} \mathrm{Mo}_{7} \mathrm{O}_{24}$ $(21 \mathrm{~g}), \mathrm{CeSO}_{4}(1 \mathrm{~g})$ and $96 \% \mathrm{H}_{2} \mathrm{SO}_{4}(31 \mathrm{~mL})$ in $500 \mathrm{~mL}$ of deionized $\mathrm{H}_{2} \mathrm{O}$, followed by heating. The catalyst was filtered off, and solvent removed in vacuo. The resulting precipitate was redissolved in $\mathrm{H}_{2} \mathrm{O}(20 \mathrm{~mL})$ and $\mathrm{EtOH}$ $(90 \mathrm{~mL})$ was added. The product crystallizes at $0^{\circ} \mathrm{C}$. The crystals were filtered off and dried in vacuo yielding $1.02 \mathrm{~g}$ of 3. Isocyanatopropyltriethoxysilane (ICPTES, $247.4 \mathrm{mg}$, $0.37 \mathrm{mmol})$ was dissolved in $\mathrm{CHCl}_{3}(5 \mathrm{~mL})$ and 3 $(0.37 \mathrm{mmol})$ was then added, followed by a solution of triethylamine $(3.34 \mathrm{mmol})$ in $\mathrm{MeOH}(10 \mathrm{~mL})$. The resultant solution was stirred overnight. Finally, the solvent was dried under vacuum, yielding $265 \mathrm{mg}$ of 4 (Additional file 1: Scheme S1) [25].

An ICPTES-NTA solution (20 $\mathrm{mg}$ in $20 \mathrm{~mL} \mathrm{EtOH}$ ) was added to the SiMNP aqueous dispersion $(33 \mathrm{~mL}$, $\mathrm{EtOH}$ ) and the mixture was heated at $80^{\circ} \mathrm{C}$ for $3 \mathrm{~h}$ under stirring. NTASiMNP were recovered after centrifugation and washed twice with $\mathrm{EtOH}$ to remove the excess of unreacted ICPTES-NTA. In the last step, $\mathrm{NiCl}_{2} \cdot 6 \mathrm{H}_{2} \mathrm{O}$ ( $95 \mathrm{mg}$ in $4 \mathrm{~mL} \mathrm{H}_{2} \mathrm{O}$ ) was added to the dispersion of NTASiMNP (20 mg in $\left.6 \mathrm{~mL} \mathrm{H}_{2} \mathrm{O}\right)$. The $\mathrm{pH}$ of the solution was adjusted to $\mathrm{pH} 8.4$ with $0.1 \mathrm{~N} \mathrm{NaOH}$ and the dispersion was sonicated for $30 \mathrm{~min}$. The nanoparticles were washed twice with water by centrifuging at $2500 \mathrm{rpm}$. The collected washed particles (NiNTASiMNP) were dissolved in water and stored at the final concentration of $5 \mathrm{mg} \mathrm{mL}^{-1}$. This procedure is briefly outlined in Figure 1, first two steps.

\section{Affinity purification of histidine-tagged CPSso}

Wild-type and mutated histidine-tagged CPSso were purified by Ni-chelate affinity chromatography. E. coli cells were grown under shaking at $37^{\circ} \mathrm{C}$ in LB medium $(3 \mathrm{~L})$ containing $0.1 \%$ glucose, $50 \mathrm{mg} \mathrm{mL} \mathrm{m}^{-1}$ ampicillin,
$25 \mathrm{mg} \mathrm{mL} \mathrm{mL}^{-1}$ choramphenicol until $\mathrm{A}_{600}$ reached 0.8 . Induction was then carried out for $3.5 \mathrm{~h}$ with $0.4 \mathrm{mM}$ isopropyl $\beta$-D-thiogalactopyranoside. Cells were harvested, washed with $50 \mathrm{mM}$ Tris- $\mathrm{HCl}, \mathrm{pH} 8.0,0.1 \mathrm{M}$ $\mathrm{NaCl}, 10 \mathrm{mM} \mathrm{ZnCl}$, and resuspended in 3 volumes of $50 \mathrm{mM}$ Tris- $\mathrm{HCl}, \mathrm{pH}$ 8.0, $1 \mathrm{mM}$ PMSF, $5 \mathrm{mM} \mathrm{2-}$ mercaptoethanol, complete EDTA-free protease inhibitor (1 tablet/50 mL; Roche), 13 units $\mathrm{mL}^{-1}$ bovine pancreas DNase (Sigma-Aldrich, St. Louis, MO). Cells were disrupted by sonication and centrifuged at $40000 \times \mathrm{g}$ for $30 \mathrm{~min}$. After addition of $10 \%$ (by vol.) glycerol and $10 \mathrm{mM}$ imidazole, the supernatant was loaded at a flow rate of $1 \mathrm{~mL} \mathrm{~min}{ }^{-1}$ onto a Ni-NTA Superflow (Qiagen) column ( $2 \mathrm{~mL}$ bed volume) pre-equilibrated with $50 \mathrm{mM}$ potassium Mes, pH 6.0, $10 \mathrm{mM}$ imidazole, $5 \mathrm{mM} \mathrm{2-}$ mercaptoethanol, $10 \%$ (by vol.) glycerol. The column was washed with 10 volumes of the same buffer and the enzyme eluted with a $20-\mathrm{mL}$ continuous linear imidazole gradient, $10 \mathrm{mM}$ to $1 \mathrm{M}$, in the same buffer, and 2-mL fractions were collected (Additional file 1: Figure S1). Fractions displaying the highest purity (at least $95 \%$, as assessed in SDS-PAGE) [41] were concentrated in Amicon Ultra 100.000 MWCO (Millipore) and buffer was exchanged to $50 \mathrm{mM}$ potassium Mes, $\mathrm{pH}$ 6.0.

\section{CPSso activity and protein assays}

CPSso activity was assayed continuously using benzoylarginine (Bz-Arg) or furylacryloyl-phenylalanine (Fur-Phe) as substrates. The assay mixture contained $50 \mathrm{mM}$ potassium Mes pH 6.5, 0.1 mM Bz-Arg or 0.2 mM Fur-Phe, in a total volume of $1.5 \mathrm{~mL}$. After a 5 -min preincubation at $60^{\circ} \mathrm{C}$ the enzyme was added, and the decrease in absorbance monitored at the same temperature and $239 \mathrm{~nm}$ or $330 \mathrm{~nm}$. At these wavelengths, the decrease of the molar absorption coefficient was $6240 \mathrm{M}^{-1} \mathrm{~cm}^{-1}$ for Bz-Arg and $5750 \mathrm{M}^{-1} \mathrm{~cm}^{-1}$ for Fur-Phe, respectively. One unit of enzyme activity is defined as the amount that hydrolyzes $1 \mu \mathrm{mol} \mathrm{min}{ }^{-1}$ of substrate under the standard assay conditions. Protein content was determined using the Coomassie Plus Protein Assay Reagent from Pierce and bovine plasma immunoglobulin $\mathrm{G}$ as the standard protein.

\section{CPSso conjugation to NiNTASiMNP}

In a plastic tube, NiNTASiMNP $(1 \mathrm{mg})$ were incubated with purified CPSso $(200 \mu \mathrm{g})$ in $50 \mathrm{mM}$ potassium Mes $\mathrm{pH} 6.5$ in a final volume of $5 \mathrm{~mL}$ and the mixture was stirred on an orbital shaker for $15 \mathrm{~min}$ at $4^{\circ} \mathrm{C}$. CPSso-MNP were isolated from unreacted CPSso by centrifugation at $5000 \times \mathrm{g}$ for $3 \mathrm{~min}$ and the supernatant was discarded. Nanoparticles were washed three times with $50 \mathrm{mM}$ potassium Mes pH $6.5(1 \mathrm{ml})$ and stored in $50 \mathrm{mM}$ potassium Mes pH 6.5 at $4^{\circ} \mathrm{C}$. By measuring the amount of protein found in the supernatant after the enzyme binding process, we determined an amount of CPSso immobilized 
on nanoparticles of $150 \mu \mathrm{g}$ per mg of MNP-CPSso. The average number of CPSso loaded on MNP-CPSso was estimated to be about 2 molecules per nanoparticle. This procedure is briefly outlined in Figure 1, last step.

\section{Assessment of CPSso stability in aqueous medium}

Free and conjugated CPSso were incubated at the desired temperatures in a thermoshaker under stirring and at a concentration of $60 \mu \mathrm{g} \mathrm{mL} \mathrm{m}^{-1}$, in $50 \mathrm{mM}$ potassium Mes, pH 6.5. At different times, protein aliquots (about $30 \mathrm{mU}$ ) were taken from the mixture and added to $1.5 \mathrm{~mL}$ of degassed $50 \mathrm{mM}$ potassium Mes, $\mathrm{pH} 6.5$, $0.1 \mathrm{mM} \mathrm{Bz}$-Arg, already thermostated in a cuvette at $60^{\circ}$ C. The reaction was monitored at $239 \mathrm{~nm}$ as previously described.

\section{Assessment of CPSso stability in dimethylformamide}

Free and conjugated CPSso were incubated at $40^{\circ} \mathrm{C}$ in a thermoshaker and at a concentration of $60 \mu \mathrm{gmL}^{-1}$, in $50 \mathrm{mM}$ potassium Mes, pH 6.5 and the indicated DMF concentrations. At different times, protein aliquots (about $30 \mathrm{mU}$ ) were taken from the mixture and added to $1.5 \mathrm{~mL}$ of degassed $50 \mathrm{mM}$ potassium Mes, $\mathrm{pH}$ 6.5, $0.2 \mathrm{mM}$ FurPhe, already thermostated in a cuvette at $60^{\circ} \mathrm{C}$. The reaction was monitored at $330 \mathrm{~nm}$ as previously described.

\section{Assessment of CPSso stability in ethanol}

Free and conjugated CPSso were incubated at $40^{\circ} \mathrm{C}$ in a thermoshaker and at a concentration of $60 \mu \mathrm{g} \mathrm{mL} \mathrm{m}^{-1}$, in $50 \mathrm{mM}$ potassium Mes, $\mathrm{pH}$ 6.5, and the indicated ethanol concentrations. At different times, protein aliquots (about $30 \mathrm{mU}$ ) were taken from the mixture and added to $1.5 \mathrm{~mL}$ of degassed $50 \mathrm{mM}$ potassium Mes, $\mathrm{pH} 6.5,0.1 \mathrm{mM}$ Bz-Arg, already thermostated in a cuvette at $60^{\circ} \mathrm{C}$. The reaction was monitored at $239 \mathrm{~nm}$ as previously described.

\section{Synthesis of $\mathrm{N}$-blocked amino acids}

A solution of $50 \mathrm{mM}$ potassium Mes, $\mathrm{pH}$ 6.5, including reaction substrates (sodium benzoate and the amino acid) and organic solvent at the desired concentration was prepared. Final volume was $40 \mu \mathrm{L}$ including enzyme and nanoparticle. Control samples were prepared with NiNTASiMNP and without CPSso. Samples and controls were incubated in a thermoshaker at the desired temperature for 6 or $24 \mathrm{~h}$. At the end of the respective incubation times, each sample was boiled at $100^{\circ} \mathrm{C}$ for $15 \mathrm{~min}$ to inactivate the enzyme.

\section{Determination of the products of synthesis}

After boiling the samples, quantitative determination of $\mathrm{N}$-blocked amino acid produced was carried out by total hydrolysis catalyzed by CPSso. Aliquots were taken from the samples, added to $2.5 \mathrm{~mL}$ of degassed $50 \mathrm{mM}$ potassium Mes, $\mathrm{pH}$ 6.5, at an appropriate dilution factor (around 1:1000) so that the initial absorbance was not greater than 1.4 absorbance units. Then, the mixture was thermostated for $10 \mathrm{~min}$ at $40^{\circ} \mathrm{C}$ and the assay performed by monitoring the decrease in absorbance at $40^{\circ} \mathrm{C}$ in the presence of $20-30 \mathrm{mU}$ of CPSso at $242 \mathrm{~nm}$. The decrease in extinction coefficients $(\Delta \varepsilon)$ for Bz-amino acids was $6058 \mathrm{M}^{-1} \mathrm{~cm}^{-1}$.

\section{Additional file}

\begin{abstract}
Additional file 1: Scheme S1. Synthesis of ICPTES-NTA. Figure S1. Progress of CPSSO purification by Ni-chelate chromatography, as monitored by SDS-PAGE (12\% gel). M: molecular weight markers with the respective molecular weights $(\mathrm{kDa})$; $\mathrm{CE}$ : crude extract; $\mathrm{FT}$ : column flow through; W: column wash; Fr1 to Fr10: individual fractions eluted by an imidazole gradient. For other details, see Materials and Methods. Table S1. CPSso binds to MNPs via NiNTA functional groups. The enzyme (ca. $1000 \mathrm{mU}$ ) was incubated in the presence of $1 \mathrm{mg}$ of MNP (NiNTASiMNP or NTASiMNP) for $15 \mathrm{~min}$ at $4^{\circ} \mathrm{C}$ under gentle shaking. Then, the mixes were centrifuged and the supernatant (containing the unbound enzyme) removed. Next, the MNPs were washed twice with $50 \mathrm{mM}$ potassium MES, 6.5. Finally, they were resuspended in the same buffer and bound activity determined. Activities in the other fractions (unbound, wash1 and wash 2) were also determined.
\end{abstract}

\section{Abbreviations}

CPSso: Sulfolobus solfataricus carboxypeptidase; DMF: Dimethylformamide; ICPTES: Isocyanatopropyltriethoxysilane; IPTES-NTA: 15-carboxy-16(carboxymethyl)-4,4-diethoxy-9-oxo-3-oxa-8,10,16-triaza-4-silaoctadecan-18oic acid-Ni ${ }^{2+}$; potassium Mes: 2-(N-Morpholino)ethanesulfonic acid potassium salt; MNP: Superparamagnetic iron oxide nanoparticles; NiNTA: Nichel nitriloacetic acid; NiNTASiMNP: $\mathrm{Ni}^{2+}$-functionalized silica-coated magnetic nanoparticles; SiMNP: Silica-coated magnetic nanoparticles;

TEM: Transmission electron microscopy; TEOS: Tetraethylorthosilicate; $\mathrm{TMAOH}$ : Tetramethylammonium hydroxide.

\section{Competing interests}

The authors declare that they no competing interests.

\section{Authors' contributions}

Conceived and designed the experiments: DP PT SS. Performed the experiments: CB EG JPA MC SS. Analyzed the data: DP MC PT SS. Wrote the paper: DP SS PT. All authors read and approved the final manuscript.

\section{Acknowledgments}

This work was supported by Regione Lombardia (NanoMeDia Project) and Fondazione Regionale per la Ricerca Biomedica, FRRB (Early System Nanotechnology).

\section{Author details}

${ }^{1}$ Dipartimento di Biotecnologie e Bioscienze, Università di Milano-Bicocca, Piazza della Scienza 2, Milano 20126, Italy. ${ }^{2}$ Istituto di Scienze e Tecnologie Molecolari, CNR, via Fantoli 16/15, Milano 20138, Italy.

Received: 10 June 2014 Accepted: 13 August 2014

Published: 5 September 2014

\section{References}

1. Colombo M, Carregal-Romero S, Casula MF, Gutiérrez L, Morales MP, Böhm IB, Heverhagen JT, Prosperi D, Parak WJ: Biological applications of magnetic nanoparticles. Chem Soc Rev 2012, 41:4306-4334.

2. Sun C, Lee JSH, Zhang M: Magnetic nanoparticles in MR imaging and drug delivery. Adv Drug Delivery Rev 2008, 60:1252-1265.

3. Weissleder R, Pittet MJ: Imaging in the era of molecular oncology. Nature 2008, 452:580-589.

4. Lee H, Sun E, Ham D, Weissleder R: Chip-NMR biosensor for detection and molecular analysis of cells. Nat Med 2008, 14:869-874. 
5. Polito L, Monti D, Caneva E, Delnevo E, Russo G, Prosperi D: One-step bioengineering of magnetic nanoparticles via a surface diazo transfer/ azide-alkyne click reaction sequence. Chem Commun 2008, 5:621-623.

6. Wang W, Xu Y, Wang DIC, Li Z: Recyclable nanobiocatalyst for enantioselectivesulfoxidation: facile fabrication and high performance of chloroperoxidase-coated magnetic nanoparticles with iron oxide core and polymer shell. J Am Chem Soc 2009, 131:12892-12893.

7. Dyal A, Loos K, Noto M, Chang SW, Spagnoli C, Shafi KVPM, UIman A, Cowman M, Gross RA: Activity of Candida rugosa lipase immobilized on $Y-\mathrm{Fe}_{2} \mathrm{O}_{3}$ magnetic nanoparticles. J Am Chem Soc 2003, 125:1684-1685.

8. Koeller KM, Wong CH: Enzymes for chemical synthesis. Nature 2001, 409:232-240.

9. Schmid A, Dordick JS, Hauer B, Kiener A, Wubbolt M, Witholt B: Industrial biocatalysis today and tomorrow. Nature 2011, 409:258-267.

10. Yiu HHP, Keane MA: Enzyme-magnetic nanoparticle hybrids: new effective catalysts for the production of high value chemicals. $J$ Chem Technol Biotechnol 2012, 87:583-594.

11. Abad JM, Mertens SFL, Pita M, Fernandez VM, Schiffrin DJ: Functionalization of thioctic acid-capped gold nanoparticles for specific immobilization of histidine-tagged proteins. J Am Chem Soc 2005, 127:5689-5694.

12. Johnson PA, Park HJ, Driscoll AJ: Enzyme nanoparticle fabrication: magnetic nanoparticle synthesis and enzyme immobilization. Methods Mol Biol 2011, 679:183-191.

13. Occhipinti E, Verderio P, Natalello A, Galbiati E, Colombo M, Mazzucchelli S, Tortora P, Doglia SM, Prosperi D: Investigating the structural biofunctionality of antibodies conjugated to magnetic nanoparticles. Nanoscale 2011, 3:387-390

14. Li D, Teoh WY, Gooding JJ, Selomulya C, Amal R: Functionalization strategies for protease immobilization on magnetic nanoparticles. Adv Funct Mater 2010, 20:1767-1777.

15. Yu CC, Kuo YY, Liang CF, Chien WT, Wu HT, Chang TC, Jan FD, Lin CC Site-specific immobilization of enzymes on magnetic nanoparticles and their use in organic synthesis. Bioconjugate Chem 2012, 23:714-724.

16. Johnson A, Zawadzka A, Deobald L, Crawford R, Paszczynski A: Novel method for immobilization of enzymes to magnetic nanoparticles. J Nanoparticle Res 2008, 10:1009-1025.

17. Colombo S, Toietta G, Zecca L, Vanoni M, Tortora P: Molecular cloning, nucleotide sequence and expression of a carboxypeptidase-encoding gene from the archaebacterium Sulfolobus solfataricus. J Bacteriol 1995, 177:5561-5565.

18. Bec N, Villa A, Tortora P, Mozhaev W, Balny C, Lange R: Enhanced stability of carboxypeptidase from Sulfolobus solfataricus at high pressure. Biotechnol Lett 1996, 18:483-48832.

19. Tortora P, Vanoni M: Sulfolobus carboxipeptidase. In Handbook of proteolytic enzymes. 2nd edition. Edited by Barrett AJ, Rawlings ND, Woessner F. London: Elsevier; 2004:953-955.

20. Occhipinti E, Bec N, Gambirasio B, Baietta G, Martelli PL, Casadio R, Balny C, Lange $R$, Tortora $P$ : Pressure and temperature as tools for investigating the role of individual non-covalent interactions in enzymatic reactions. Sulfolobus solfataricus carboxypeptidase as a model enzyme. Biochim Biophys Acta 2006, 1764:563-572

21. Occhipinti E, Martelli PL, Spinozzi F, Corsi F, Formantici C, Molteni L, Amenitsch H, Mariani P, Tortora P, Casadio R: 3D structure of Sulfolobus solfataricus carboxypeptidase developed by molecular modeling is confirmed by site-directed mutagenesis and small-angle X-ray scattering. Biophys J 2003, 85:1165-1175.

22. Sommaruga S, De Palma A, Mauri PL, Trisciani M, Basilico F, Martelli PL, Casadio R, Tortora P, Occhipinti E: A combined approach of mass spectrometry, molecular modeling, and site-directed mutagenesis highlights key structural features responsible for the thermostability of Sulfolobus solfataricus carboxypeptidase. Proteins 2008, 71:1843-1852.

23. Colombo S, D'Auria S, Fusi P, Zecca L, Raia CA, Tortora P: Purification and characterization of a thermostable carboxypeptidase from the extreme thermophilic archaebacterium Sulfolobus solfataricus. Eur J Biochem 1992 206:349-357.

24. Corsi F, Fiandra L, De Palma C, Colombo M, Mazzucchelli S, Verderio P, Allevi R, Tosoni A, Nebuloni M, Clementi E, Prosperi D: HER2 expression in breast cancer cells is downregulated upon active targeting by antibody-engineered multifunctional nanoparticles in mice. ACS Nano 2011, 5:6383-6393.
25. Mazzucchelli S, Verderio P, Sommaruga S, Colombo M, Salvade A, Corsi F, Galeffi P, Tortora P, Prosperi D: Multiple presentation of Scfv800E6 on silica nanospheres enhances targeting efficiency toward HER-2 receptor in breast cancer cells. Bioconjugate Chem 2011, 22:2296-2303.

26. Hwang ET, Gang H, Chung J, Gu MB: Carbonic anhydrase assisted calcium carbonate crystalline composites as a biocatalyst. Green Chemistry 2012, 8:2216-2220.

27. Mazzucchelli S, Colombo M, De Palma C, Salvadè A, Verderio P, Coghi MD, Clementi E, Tortora P, Corsi F, Prosperi D: Synthesis of single-domain protein A-engineered magnetic nanoparticles: toward a universal strategy to site-specific labeling of antibodies for targeted detection of tumor cells. ACS Nano 2010, 4:5693-5702.

28. Colombo M, Mazzucchelli S, Collico V, Avvakumova S, Pandolfi L, Corsi F, Porta F, Prosperi D: Protein-assisted one-pot synthesis and biofunctionalization of spherical gold nanoparticles for selective targeting of cancer cells. Angew Chem Int Ed 2012, 51:9272-9275.

29. Colombo M, Mazzucchelli S, Montenegro JM, Galbiati E, Corsi F, Parak WJ, Prosperi D: Protein oriented ligation on nanoparticles exploiting O6-alkylguanine-DNA transferase (SNAP) genetically encoded fusion. Small 2012, 8:1492-1497.

30. Colombo M, Sommaruga S, Mazzucchelli S, Polito L, Verderio P, Galeffi P, Corsi F, Tortora P, Prosperi D: Site-specific conjugation of scFv antibodies to nanoparticles by bioorthogonal strain-promoted alkynenitronecycloaddition. Angew Chem Int Ed 2012, 51:496-499.

31. Baietta G: La carbossipeptidasi dall'archaeon Sulfolobus solfataricus: un enzima termostabile che promuove la sintesi del legame peptidico in solvente organico. Master's Degree Thesis: University of Milan; 2000.

32. Dias CL, Ala-Nissila T, Wong-ekkabut J, Vattulainen I, Grant M, Karttunen M: The hydrophobic effect and its role in cold denaturation. Cryobiology 2010, 60:91-99.

33. Villa A, Zecca L, Fusi P, Colombo S, Tedeschi G, Tortora P: Structural features responsible for kinetic thermal stability of a carboxypeptidase from the archaebacterium Sulfolobus solfataricus. Biochem J 1993, 295:827-831.

34. Olofsson L, Söderberg P, Nicholls IA: Influence of water miscible organic solvents on alpha-chymotrypsin in solution and immobilized on Eupergit CM. Biotechnol Lett 2006, 28:929-935.

35. Mattos C, Ringe D: Proteins in organic solvent. Curr Opin Struct Biol 2001, 11:761-764.

36. Khmelnitsky YL, Mozhaev W, Belova AB, Sergeeva MV, Martinek K: Denaturation capacity: a new quantitative criterion for selection of organic solvents as reaction media in biocatalysis. Eur J Biochem 1991, 198:31-41.

37. Bongers J, Heimer EP: Recent applications of enzymatic peptide synthesis. Peptides 1994, 15:183-193.

38. Carrea G, Riva S: Properties and synthetic applications of enzymes in organic solvents. Angew Chem Int Ed 2000, 39:2226-2254.

39. Liong M, Shao H, Haun JB, Lee H, Weissleder R: Carboxymethylated polyvinyl alcohol stabilizes doped ferrofluids for biological applications. Adv Mater 2010, 22:5168-5172.

40. Schmitt L, Dietrich C, Tampe R: Synthesis and characterization of chelator-lipids for reversible immobilization of engineered proteins at self-assembled lipid interfaces. J Am Chem Soc 1994, 116:8485-8492.

41. Laemmli UK: Cleavage of structural proteins during the assembly of the head of bacteriophage T4. Nature 1970, 227:680-685.

doi:10.1186/1472-6750-14-82

Cite this article as: Sommaruga et al:: Immobilization of carboxypeptidase from Sulfolobus solfataricus on magnetic nanoparticles improves enzyme stability and functionality in organic media. BMC Biotechnology 2014 14:82. 